\title{
Teaching Reform and Practice of Ornamental Botany Course in Tourism Management (Ecotourism)
}

\author{
Wang Wenhea , He Xiangfeng, Zhang Ruili, Zhao Yazhou, Guan Xuelian \\ School of Landscape Architecture \\ Beijing University of Agriculture \\ Beijing 102206 \\ awwhals@163.com
}

\begin{abstract}
This paper analyzed the complex content and poor effectiveness in practical teaching of "Ornamental Botany" which is widely opened in China's Tourism Management specialty. The paper proposed to streamline curriculum content according to the orientation of ecotourism. Deliver introduction with vivid cases to arouse students' interest in learning. Create a good atmosphere of interaction between teachers and students. Increase observation of phenology and reform experimental teaching. Enhance the difficulty of schoolwork and reform practice teaching. Integrate plant culture to the entire curriculum, and practice, and achieve good teaching results eventually.
\end{abstract}

Keywords-Ornamental botany; Theory teaching; Practice teaching; Teaching reform

\section{INTRODUCTION}

"Ornamental Botany” is a comprehensive subject which focuses on ornamental plant's classification, habits, distribution and origin, reproduction and cultivation, as well as the application of landscape science and technology ${ }^{[1]}$. It is a basic professional course of Tourism Management specialty (ecotourism) of Beijing University of Agriculture. The curriculum system and the cultivation target highlight the characteristics of plant resources and ecology, and the role in the curriculum system in tourism management attracts more and more attention. Ornamental Botany is a comprehensive curriculum, which is based on the form and classification of the traditional "Botany", and takes in the curriculum content of "Garden Dendrology", "Floriculture", "Garden Plants Cultivation and Maintenance", "Plant Landscaping Art" and "Plant Culture". Since the course was open for sophomore students in the third semester, they are not clear about the importance of it in tourism management courses and practical work, and have no relevant botanical knowledge background. Therefore, the key to teaching reform of the course is how to combine the extensive curriculum content and the professional training objectives organically, and how to improve students' interest in learning and acceptance ability to achieve good teaching effect, so that the tourism management students can better apply the knowledge acquired in ornamental botany to the development of plant resources, mining and utilization of tourist attractions

Fund project: Beijing University of Agriculture 2018 Education and Teaching Reform Research Project (BUA2018JG046-047) and be able to publicize botany knowledge and culture in the tour guide and achieve the ecotourism.

\section{EXISTING PROBLEMS}

From 2010 onwards, Tourism Management department has set Ornamental Botany. According to of talent training objectives of the eco-tourism in Tourism Management specialty, after discussions on courses system setting and course content scope, the College Instructional Guidance Committee decided to choose the "Ornamental Botany" edited by Li Jingxia as a reference material ${ }^{[1]}$. This book has a total of 8 chapters with 34 sections, which meets the professional requirements. However, as each chapter of the textbook is detailed, covering complex content, which are comprehensive and systematic, students have difficulties in mastering in a short time. Therefore, teachers need in-depth study to address this issue.

\section{A. The effect of traditional practice teaching is poor}

"Ornamental Botany" is a highly practical course. If the practical teaching effect is poor, the overall learning effect of the course is greatly discounted, and the course is a waste when students forget the knowledge memorized after graduating as they do not have a deep impression on them.

In Beijing University of Agriculture, the "Ornamental Botany" has a total of 64 class hours including 48-hour theoretical class, 16-hour experimental teaching (8 experiments), and 3-day internship. As for the traditional experimental teaching, the experiment staff gathers some flowers and fruits of ornamental plants by collecting on the campus and purchasing in flower market and teachers lead students to observe in the laboratory. However, as the observation material is limited and the plant material is static, students gradually lose interest and the teaching effect decreases. Internship generally includes 1 day on campus, 1 day in Botanical Garden, and 1 day in Park. The junior students have the wrong understanding of the open and comprehensive teaching, as most of them think that course is following teachers to go sightseeing, which greatly undermines the teaching effect. Moreover, 2 teachers face more than 60 students. The lecturer, from a certain location explain each 
ornamental plant in identification points, habits, reproduction, ornamental characteristics and usage, during which students are only passively accept and rote learning. As a result, they get tired after 1 to 2 hours, and due to various environmental factors around, they become absent-minded and even stay away from teachers, do not or unable to listen to the teacher or observe the details of ornamental plants. Given this, though the teacher gets very tired, the practical teaching effect of practice is poor.

\section{REFORM MEASURES}

\section{A. To streamline the teaching content}

Although the content of "Ornamental Botany" is complex, extensive, and prone to confuse students, the teaching content can be completed within the limited class hours. As the forest ecology is the specialized courses for Tourism Management major (ecotourism), the third chapter of ornamental plants and the environment can be omitted. The fourth chapter decoration and application of ornamental plants is left for the students to study after class and make PPT themselves. This chapter is included in the optional course - "Flower Arrangement " . The fifth chapter is the allocation of ornamental plants, the principles and basic forms of which can be summarize in one hour, with the detailed content being taught in the optional course "Green Space Planning". The eighth chapter "Lawn and Ground Plants" does not require students to master, and just a general understanding is enough. After streamlining, the course content just focuses on the introduction, the first chapter "ornamental plant morphology and classification", the second chapter "growth and breeding of ornamental plants", the sixth chapter "woody ornamental plants", and the seventh chapter "herbal ornamental plants".

\section{B. The introduction, arouse the students' interest in learning}

During the teaching, we found that the students major in Tourism Management of Beijing University of Agriculture do not have good understanding of the characteristics of ecological tourism, and the relationship among the curricula, and have no relevant botanical knowledge background, so students think that ornamental botany is of little use in the employment. The bias results in a poor learning motivation. Therefore, how to improve the students' interest in the study of Ornamental Botany becomes the primary problem in this course. The role of the introductory course is crucial in stimulating the student's motivation and learning aspirations. ${ }^{[2]}$ Therefore, in addition to domestic rich ornamental plant resources and the long history of cultivation, we introduce the famous botanical gardens, scenic spots and flower field. For example, we have listed the Royal Botanic Garden - Kew Gardens recognized as the world cultural heritage by the United Nations, New York Botanical Garden, Holland Keukenhof Park and other famous foreign botanical gardens, and China's 5 A tourist attraction Shenyang Botanical Garden, 4 A tourist attraction - Beijing Botanical Garden, Xinglong Tropical Plant Park, etc. The scenic spots range from Huangshan greeting pine, Luoyang Peony, Kaifeng chrysanthemum, Nanjing "Plum Blossom Hill”, Wuhan University Sakura to Beijing Xiangshan's maple leaves, Beihai Park lacebark pine, and so on. All these make students know that ornamental plants can also be the core of tourism, arouse students' interest in learning and build the confidence of learning ornamental plants. And the role of ornamental plants in the tourism industry becomes more and more important with the advocating for returning to the nature and proposals like "Beautiful China”, "Rural complex” raised in recent years.

\section{Create a good interaction between teachers and students}

Teachers should take an effective interactive teaching method, so that students actively participate in the curriculum ${ }^{[3]}$. The survey of tourism management students in the university found that about $40 \%$ students came from provinces outside Beijing like Yunnan, Xinjiang, Guizhou, and Inner Mongolia. Most of the students in Beijing who have never been there are all longing for them. Therefore, teachers can arrange 5 minutes for students to share their local famous botanical attractions, famous plants, and the unique plant culture and so on without interrupting the normal teaching plan. For example, Students from Yunnan Province told us the Big Banyan that can make a forest. The Uygur students in Xinjiang taught us how to use "Ottoman" to draw eyebrows, use "Haina Guli" paint nails red, and use "Yilimu” oil for make-up. Guizhou classmate told how the colored glutinous rice is dyed by different plants; student from Inner Mongolia Alashan introduced how to artificially grow the famous Chinese herbal cistanche, etc. Each theme was exciting and fascinating.

Additionally, when teachers teach the professional terminology of botany, they can let one or more students use gestures to mimic (palm represents the leaves) the opposite decussate leaves, pinnately compound leaf, palmately compound leaf and ternately compound leaf etc. Divide the content of chapter 4 for students in group to research and make PPT. Spend two hours on arranging all students in every group to display on the platform. Teachers attach great importance to the above-mentioned activities and record the entire process with video, and to give positive comments. These measures not only form an active classroom interaction between teachers and students, but also extend the classroom to the library, to the Internet, greatly arousing the students' initiative of learning. The relationship among students becomes more harmonious, and forms the habits of mutual learning. The knowledge that is hard to recite becomes vivid and memorable. Undoubtedly, the classroom teaching has received good results.

\section{Reform experimental teaching}

Improving teaching method is an important way to improve teaching quality ${ }^{[4]}$. In the experimental teaching, we arrange 5 experiments outside the laboratory on campus, 3 of which are completely arranged by the students themselves; however, they are required to observe one arbor, one shrub, and one herbaceous. The teacher gives students a basic sample table. Students must complete the table according to the specificity of their plant, and record at least 10 times of phenological characteristics from March to June each plant, and hand on 3 phenology tables in mid-June, and phenological display PPT courseware. At very beginning, students passively observed and gradually they cherish flowers and trees and became active. Each student observes and records for more than 6 hours. More importantly, students really mastered some of the plant growth 
and development laws, understand the relationship between plants and the environment, learnt the truth, and even revised the world view.

In addition to the morphological observation of ornamental plants, we pay more attention to anatomical structure research, and require students to touch the texture of the plant organs or tenacity, taste and smell certain plants, even listen to pine wind, listen to rain, listen to bamboo, and listen to petals falling. This kind of mobilization of human organs is good for the experimental class, and the students feel profoundly.

\section{E. Reform Practice teaching}

Thought is the basis of behavior; behavior is the expression of thought ${ }^{[5]}$. First of all, teachers should emphasize the importance of field practice, and then make the contents and requirements of the internship clear, put forward the extent and scope of knowledge, and inform the students of assessment methods and scoring principles. In this way, they can strengthen the difficulty and challenge of practice in task, eliminate the wrong understanding that field practice is sightseeing. Practice proved that posing high pressure on school can reap good internship effect and students can gain a lot.

In addition, we need to add professional teachers to guide internship, to ensure that each class (30 students) is equipped with 1 principle and 1 auxiliary teacher. This can ensure that the field teaching is less affected by other environmental factors, improve the effective management and supervision from the behavior norm, and make the students feel pressure. The auxiliary teacher can also avoid the wrong information understanding of the students in the back.

Comprehensively assess the students' disciplinary performance, learning attitude and comprehensive quality. Examine the ability of students to identify ornamental plants and to produce specimen production on site. Comprehensively examine the overall level of students' internship report and improve their ability of analysis and induction and professional writing. Notice that students grow both physically and emotional and acquire knowledge from the internship report.

\section{F. Emphasizing the introduction of plant culture in the whole process of teaching and}

Plant culture is an integral part of the broad and profound Chinese culture. The plant carries human cultural information, and becomes people's emotion sustenance and the symbol of noble character. China is a country with rich biodiversity, and has developed a unique plant culture along with the development of Chinese civilization. ${ }^{[6]}$ In the course of Ornamental Botany, we pay more attention to the introduction of plant culture, including bamboo culture, plum culture, orchid culture, chrysanthemum culture, and other plant cultures with traditional Chinese characteristics, as well as the introduction of idioms, allusions, folklore and so on. That we introduce the contents of plant culture in theory, experiment and practice teaching, not only enriches the teaching process, but also arouses the students' interest in learning, and enhances the students' humanistic quality and the emotion of "familycountry”.

\section{ConClusion}

With the development of society and subject, as well as the requirement of the new era to the talents quality of different orientation of Tourism Management specialty, the "Ornamental Botany" must explore the reform and practice of the corresponding talents training goal. "Ornamental Botany" is the basic course of ecotourism of Tourism Management specialty in Beijing University of Agriculture, which has a strong comprehensiveness and practical application, and plays an important role in the cultivation of applied high-quality professional talents for ecotourism. It has been proved that the teaching reform adopted by teachers of Ornamental Botany of Beijing University of Agriculture is successful. The reform was aimed at the complex teaching content and poor effectiveness of traditional practical teaching. The reform not only improves the teaching quality and teaching effect, but also stimulates the students' interest in learning, adapts to the requirements of ecotourism management personnel training, so that students can apply the knowledge of ornamental botany to the development, excavation and utilization of plant resources in the practical work in scenic spots. And they can publicize the knowledge and culture of ornamental plants well in the tour guide, thus achieving the purpose of ecotourism.

\section{REFERENCES}

[1] Li Jingxia, Kangyongxiang. Ornamental Botany [M]. China Forestry Publishing House, Beijing: 2005

[2] Yang Zhoujuan, Yang Xiaodong. On the introduction teaching of college curriculum [J]. Chinese University Teaching, 2011 (12): 39-41.

[3] Tan Li. Research on interactive teaching methods in universities [J]. Science \& Technology Information, 2011 (19): 591-592.

[4] Ma Shuxia, Li Wenyan, Zang Zhendong. Discussion on the function of teaching method in teaching [J] Contemporary Manager, 2006 (8): 127128

[5] Shao Ruizhen, Pi Liansheng, Wu Qinglin. Educational psychology [M] Shanghai: Shanghai Education Publishing House, 2000:6

[6] Wang Quanquan. The ecological aesthetics value of Chinese plant culture [J]. Journal of Nanjing Forestry University (Humanities and Social Sciences Edition), 2017,1:40-52 